\title{
Practical Enantioselective Reduction of Ketones Using Oxazaborolidine Catalysts Generated In Situ from Chiral Lactam Alcohols
}

\author{
Yasuhiro Kawanami * and Ryo C. Yanagita \\ Department of Applied Biological Science, Faculty of Agriculture, Kagawa University, Miki-cho, \\ Kagawa 761-0795, Japan; charlesy@ag.kagawa-u.ac.jp \\ * Correspondence: kawanami@ag.kagawa-u.ac.jp; Tel.: +81-87-891-3088 \\ Academic Editor: Alejandro Baeza Carratalá \\ Received: 21 August 2018; Accepted: 18 September 2018; Published: 20 September 2018
}

\begin{abstract}
Oxazaborolidine catalyst (CBS catalyst) has been extensively used for catalytic borane reduction with a predictable absolute stereochemistry and high enantioselectivity. However, the use of isolated CBS catalyst sometimes has the drawback of low reproducibility due to the aging of the CBS catalyst during storage. Therefore, we investigated a more reliable and practical method for the reduction of a variety of ketones including challenging substrates, primary aliphatic ketones, $\alpha, \beta$-enones, and trifluoromethyl ketones. This review surveys the developments in borane reduction using oxazaborolidine catalysts generated in situ from chiral lactam alcohols and borane.
\end{abstract}

Keywords: borane; reduction; asymmetric synthesis; enantioselective; lactam alcohol

\section{Introduction}

Asymmetric reduction of prochiral ketones is one of the most important methods for the synthesis of chiral secondary alcohols and constitutes a valuable step in the synthesis of a variety of natural products and several medicinally important compounds. The oxazaborolidine-catalyzed asymmetric borane reduction of prochiral ketones (CBS reduction) using chiral amino alcohols [1-4] has been extensively investigated, since the stoichiometric reductions were reported by Itsuno et al. [5-7] and the catalytic versions were reported by Corey et al. [8]. The chiral amino alcohol, $(S)-\alpha, \alpha$-diphenyl-2-pyrrolidinemethnol (1) derived from $(S)$-proline has been widely accepted as superior one that permits efficient synthesis of chiral secondary alcohols with predictable absolute stereochemistries (Figure 1). However, it has been described that the preparation of oxazaborolidine 1a requires heating at reflux with excess $\mathrm{BH}_{3}$ in tetrahydrofuran (THF) [4]. On the other hand, Quallich et al. reported that the reaction of $\mathbf{1}$ with excess borane-dimethyl sulfide complex $\left(\mathrm{BH}_{3}-\mathrm{Me}_{2} \mathrm{~S}\right)$ formed the oxazaborolidine 1a in THF at room temperature for 8-10 h (Scheme 1) [9]. Later, Yanagi et al. also reported that the catalyst $\mathbf{1 a}$ was generated from $\mathbf{1}$ and $\mathrm{BH}_{3}-\mathrm{Me}_{2} \mathrm{~S}$ in THF, ether, and hexane at room temperature for $1 \mathrm{~h}$ [10]. Although the B-Me oxazaborolidine $\mathbf{1} \mathbf{b}$ formed by the reaction of 1 with methylboronic acid has been developed as an air- and moisture- stable catalyst that catalyzes the borane reduction of ketones with an excellent enantioselectivity [11], there is the requirement of complete removal of water to avoid undesired effects [12]. As part of our studies in asymmetric synthesis, we have investigated a more convenient and practical method for the reduction of a variety of ketones. This review surveys the developments in borane reduction using in situ generated oxazaborolidine catalysts from chiral lactam alcohols and borane over the last fifteen years. Furthermore, modifications of the method are described for the borane reduction of challenging substrates, i.e., primary aliphatic ketones, $\alpha, \beta$-enones and trifluoromethyl ketones. 
<smiles>OC(c1ccccc1)(c1ccccc1)C1CCCN1</smiles>

1<smiles>[R]B1OC(c2ccccc2)(c2ccccc2)C2CCCN12</smiles>

1a $\mathrm{R}=\mathrm{H}$ $1 \mathrm{~b} R=\mathrm{Me}$ $1 \mathrm{c} \mathrm{R}=n-\mathrm{Bu}$<smiles>O=C1CCC(C(O)(c2ccccc2)c2ccccc2)N1</smiles>

2

Figure 1. Various chiral catalysts and precatalysts.<smiles>OC(c1ccccc1)(c1ccccc1)C1CCCN1</smiles>

1

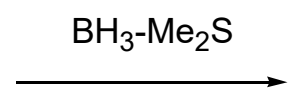

$1 \mathrm{a}$

Scheme 1. Generation of oxazaborolidine 1a in situ from 1 and borane.

\section{Oxazaborolidine Catalyst Generated In Situ from a Chiral Lactam Alcohol and Borane}

To overcome certain drawbacks, such as difficulties in handling and the reproducibility of the isolated oxazaborolidine catalysts, an alternative method was needed. We considered that the chiral lactam alcohol 2 [13], (S)-5-(diphenylhydroxymethyl)pyrrolidin-2-one, could be rapidly reduced with borane to the corresponding imine, which would be further reduced by the neighboring alkoxyborane to form the oxazaborolidine 1a (Scheme 2). This was inferred from the report that the racemic amino alcohol 1 could be prepared from the racemic lactam alcohol 2 through its reduction with borane [10].<smiles>CC(C)C1(c2ccccc2)CCCN1BBOC(c1ccccc1)(c1ccccc1)C1CCC=N1</smiles>

Scheme 2. Generation of oxazaborolidine 1a in situ from 2 and borane.

Therefore, we conducted ${ }^{11} \mathrm{~B}$ NMR analysis of the in situ generated oxazaborolidine catalyst as shown in Figure 2. The ${ }^{11} \mathrm{~B}$ NMR $\left(\mathrm{CDCl}_{3}\right)$ spectrum indicated the presence of the oxazaborolidine complex with borane $(+17.7 \mathrm{ppm}$ and $-13.2 \mathrm{ppm})$ and free oxazaborolidine (+27.2 ppm) [14]. These chemical shifts were mostly consistent with those of the oxazaborolidine 1a generated in situ from (S)-diphenylpyrrolidinemethanol and borane [10] under the same conditions.

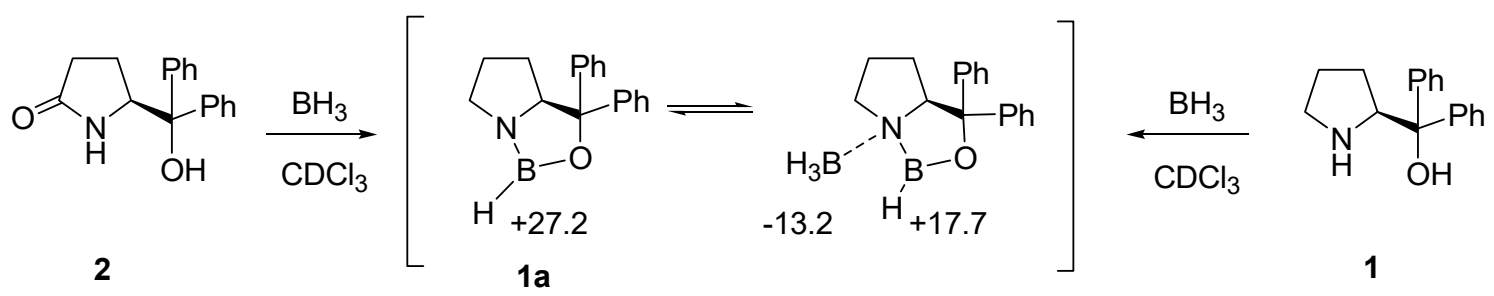

Figure $2 .{ }^{11} \mathrm{~B}$ NMR shifts.

As a result, we expected that the oxazaborolidine 1a generated in situ from 2 and borane should possibly catalyze the reduction of prochiral ketones with high enantioselectivities. 


\section{Asymmetric Reduction of Ketones}

The lactam alcohol 2 was readily prepared by the reaction of phenylmagnesium bromide with methyl (S)-pyroglutamate as reported previously [13]. The reduction of the chiral lactam alcohol 2 (10 mol\%) with 1 equivalent of $\mathrm{BH}_{3}$-THF smoothly proceeded at room temperature within 5 min. We found that the resulting oxazaborolidine intermediate catalyzed the borane reduction of various ketones, affording chiral secondary alcohols in good yields and enantiomeric excess (ee). The results are summarized in Scheme 3 [15].<smiles>[R]C([R])=O</smiles><smiles>CO[R10](C)=O</smiles><smiles>[R]C([R])O</smiles><smiles>C[C@H](O)c1ccccc1</smiles><smiles>CC[C@H](O)c1ccccc1</smiles><smiles>C[C@H](O)c1ccc(Cl)cc1</smiles><smiles></smiles>
$80 \%, 91 \%$ ee $96 \%, 97 \%$ ee<smiles>O[C@H](CCl)c1ccccc1</smiles>
$97 \%, 97 \%$ ee<smiles>O[C@H]1CCCc2ccccc21</smiles><smiles>C[C@@H](O)C(C)(C)C</smiles><smiles>C[C@@H](O)C1CCCCC1</smiles><smiles>C[C@H](O)CCc1ccccc1</smiles>
$84 \%, 85 \%$ ee $86 \%, 89 \%$ ee $87 \%, 81 \%$ ee

$90 \%, 69 \%$ ee

Scheme 3. Asymmetric reduction of ketones using chiral lactam alcohol 2. All reactions were carried out with $10 \mathrm{~mol} \%$ of 2 and 1.0 equiv of $\mathrm{BH}_{3}$ in THF at room temperature.

The reduction of aryl methyl, ethyl, and chloromethyl ketone with borane and $10 \mathrm{~mol} \%$ of 2 afforded the corresponding $(R)$-secondary alcohols, except for (S)-2-chloro-1-phenylethanol, with excellent enantioselectivities (91-98\% ee). $\alpha$-Tetralone, a cyclic aryl ketone, was reduced with good enantioselectivity ( $85 \%$ ee). The reduction of alkyl methyl ketones having a tertiary, secondary, and primary alkyl group proceeded with good to moderate enantioselectivities (89\% ee, 81\% ee, and $69 \%$ ee, respectively). Thus, the yields and enantioselectivities of the reduction using the lactam alcohol 2 and borane were comparable to those of the isolated catalyst 1a. Moreover, $\mathbf{1}$ could be obtained in good yield by extraction from aqueous acidic solution after quenching, suggesting that the lactam alcohol 2 was reduced by borane to actually generate the catalyst 1a in situ at room temperature in a short time.

\section{Asymmetric Reduction of Aliphatic Ketones}

Although the reduction of most aromatic ketones proceeded with excellent enantioselectivities, those of aliphatic ketones, in particular primary aliphatic ketones, usually afforded moderate enantioselectivities. For example, the enantioselectivity for the reduction of benzylacetone using 1a generated in situ from the chiral lactam alcohol 2 and borane was only 69\% ee (that of Me-CBS $\mathbf{1 b}$ was $64 \%$ ee under the same reaction condition). Accordingly, we decided to modify the catalytic borane reduction using chiral lactam alcohol 2 to improve the enantioselectivity of the reduction of aliphatic ketones which are challenging substrates [16].

Shioiri et al. reported that trimethyl borate improved the reactivity and enantioselectivity of CBS reduction through the B-OMe oxazaborolidine 1d [17]. Therefore, we expected that the electronic effects of the boron substituent of the oxazaborolidine should enhance the reactivity and enantioselectivity. First, $\mathrm{BH}_{3}$-THF solution was added dropwise to various alcohols in THF and stirred for 20 min at 
room temperature. During this period, the generation of $\mathrm{H}_{2}$ was observed. Then, the chiral lactam alcohol 2 (10 mol\%) was added to the alkoxyborane solution and stirred further for $1 \mathrm{~h}$ (Figure 3). Slow addition of benzylacetone as an aliphatic ketone to the catalyst generated in situ for $1 \mathrm{~h}$ afforded a $(R)$-secondary alcohol in good yields (74-90\%, Scheme 4$)$. While addition of neither methanol nor 2-propanol improved ee (69\% ee, without the alcohols), the addition of substituted phenols afforded equal to slightly higher enantioselectivities (69-73\% ee). We found a nonlinear dependence of enantioselectivity on the $\mathrm{p} K_{\mathrm{a}}$ of these phenols [18]. The most acidic $p$-(trifluoromethyl)phenol did not provide superior results ( $70 \%$ ee) and $p$-iodophenol provided the highest result (73\% ee). These results suggest that $p$-iodophenoxy oxazaborolidine 1e has appropriate properties to increase the reactivity and enantioselectivity, though the reaction mechanism is very complicated due to possible involvement of several intermediate borane species. When $p$-iodophenol was added to the in situ generated 1a, the enantioselectivity decreased from $73 \%$ ee to $67 \%$ ee. This result indicated that the reduction of 2 with $p$-iodophenoxyborane should generate B-OAr oxazaborolidine catalyst $1 \mathbf{e}$, though the detection of $1 \mathbf{e}$ by ${ }^{11} \mathrm{~B}$ NMR analysis has not been successful, possibly due to its instability.

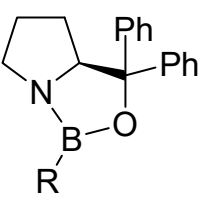

$\begin{aligned} & \text { 1a } R=\mathrm{H} \\ & \text { 1b } \mathrm{R}=\mathrm{Me} \\ & \text { 1c } \mathrm{R}=n-\mathrm{Bu} \\ & \text { 1d } \mathrm{R}=\mathrm{OMe} \\ & \text { 1e } \mathrm{R}=\mathrm{O}-\mathrm{-}-\mathrm{I}-\mathrm{Ph}\end{aligned}$

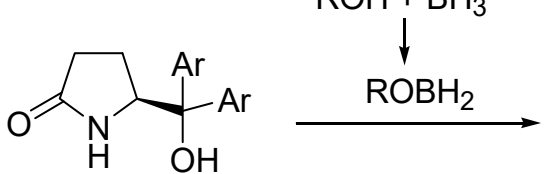

$2 \mathrm{Ar}=\mathrm{Ph}$

$3 \mathrm{Ar}=3,5-\mathrm{Me}_{2} \mathrm{Ph}$

Figure 3. Various chiral catalysts and precatalysts.<smiles>CC(=O)CCc1ccccc1</smiles>

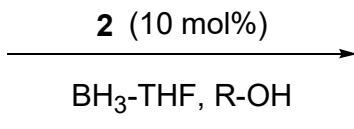

$$
\begin{array}{ll}
\mathrm{MeOH} & : 90 \%, 64 \% \text { ee } \\
\text { i-PrOH } & : 89 \%, 69 \% \text { ee } \\
\mathrm{PhOH}^{\mathrm{b}} & : 86 \%, 71 \% \text { ee } \\
\text { p-MeO-PhOH }^{\mathrm{C}}: 74 \%, 69 \% \text { ee } \\
\text { p-Br-PhOH }
\end{array}
$$

Scheme 4. Asymmetric reduction a of benzylacetone using chiral lactam alcohol 2. ${ }^{\text {a }}$ All reactions were carried out with $10 \mathrm{~mol} \%$ of 2 and 1.2 equiv of $\mathrm{BH}_{3}$ and $\mathrm{ROH}$ in THF at room temperature. ${ }^{\mathrm{b}} \mathrm{p} K_{\mathrm{a}} 9.99$. ${ }^{\mathrm{c}} \mathrm{p} K_{\mathrm{a}}$ 10.10. ${ }^{\mathrm{d}} \mathrm{p} K_{\mathrm{a}}$ 9.17. ${ }^{\mathrm{e}} \mathrm{p} K_{\mathrm{a}}$ 9.21. ${ }^{\mathrm{f}} \mathrm{p} K_{\mathrm{a}} 8.68$.

The screening of new chiral lactam alcohols with the 4-substituted or 3,5-disubstituted phenyl of the carbinol center revealed that the use of 3 with 3,5-dimethylphenyl improved the enantioselectivity from 73 to $79 \%$ ee. A nonlinear temperature effect on the enantioselectivity was also observed (Scheme 5). When the reaction temperature decreased from $20^{\circ} \mathrm{C}$ to $-20^{\circ} \mathrm{C}$, the enantioselectivity gradually increased up to $83 \%$ ee, and then dropped to $75 \%$ ee at $-40{ }^{\circ} \mathrm{C}$. This temperature effect contrasts with the reported result that general CBS reduction at lower temperature yielded lower 
enantioselectivities [19]. Therefore, we confirmed that the reduction with $3(10 \mathrm{~mol} \%)$ and $\mathrm{BH}_{3}$ (1.2 equiv) at $-20{ }^{\circ} \mathrm{C}$ resulted in a decrease in enantioselectivity, 35\% ee, implying that a new oxazaborolidine catalyst 1e would generate from 3 and $p$-iodophenoxyborane.<smiles>CC(=O)CCc1ccccc1</smiles>

$$
\begin{array}{r}
\frac{3(10 \mathrm{~mol} \%)}{\mathrm{BH}_{3}-\mathrm{THF}, p-\mathrm{IPhOH}} \\
20{ }^{\circ} \mathrm{C}: 86 \%, 79 \% \text { ee } \\
0{ }^{\circ} \mathrm{C}: 81 \%, 82 \% \text { ee } \\
-20{ }^{\circ} \mathrm{C}: 82 \%, 83 \% \text { ee } \\
-40{ }^{\circ} \mathrm{C}: 79 \%, 75 \% \text { ee }
\end{array}
$$

Scheme 5. Effect of temperature on enantioselectivity for the reduction of benzylacetone using 3 and p-iodophenoxyborane. All reactions were carried out with $10 \mathrm{~mol} \%$ of 3 and 1.2 equiv of $\mathrm{BH}_{3}$ and $p$-iodophenol in THF at room temperature.

Under these optimized reaction conditions, the reduction of alkyl methyl ketones having a tertiary, secondary, and primary alkyl group with $\mathbf{3}$ and $p$-iodophenoxyborane proceeded with excellent to good enantioselectivities (98\% ee, 81\% ee, and $83 \%$ ee, respectively; Scheme 6 ). The reduction of cyclohexyl methyl ketone at room temperature proceeded with a better enantioselectivity ( $90 \%$ ee) contrary to that involving the other ketones, suggesting that the temperature effect is somewhat substrate-specific.

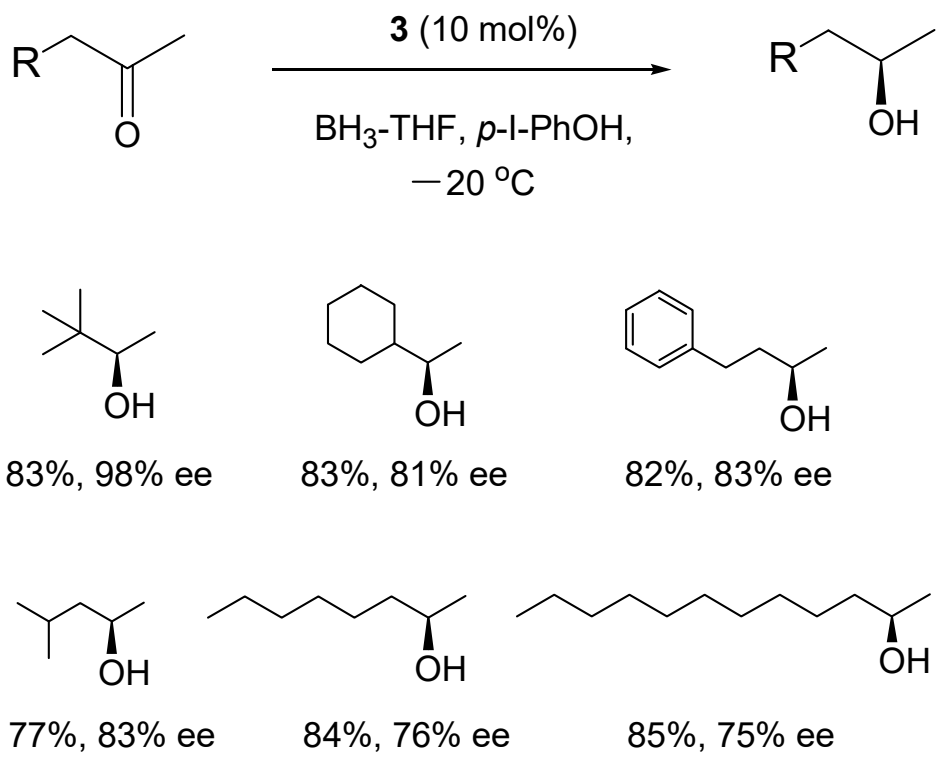

Scheme 6. Asymmetric reduction of aliphatic ketones using the chiral lactam alcohol 3 and p-iodophenoxyborane. All reactions were carried out with $10 \mathrm{~mol} \%$ of 3 and 1.2 equiv of $\mathrm{BH}_{3}$ and $p$-iodophenol in THF at $-20^{\circ} \mathrm{C}$.

\section{Asymmetric Reduction of $\alpha, \beta$-Enones}

Chiral allylic alcohols are important natural products [11] and the key intermediates for many stereospecific reactions, such as Claisen rearrangement [20], epoxidation [21], and $\mathrm{S}_{\mathrm{N}} 2^{\prime}$ displacement with organometallic regents [22]. However, the reports concerning oxazaborolidine catalysis for the reduction of $\alpha, \beta$-enones are very limited, probably due to the occurrence of a side reaction, i.e., hydroboration. For example, Corey et al. reported that the reduction of benzalacetone with Bu-CBS 1c (10-15 mol\%) and 2 equiv. of catecholborane (CB) in toluene at $-78^{\circ} \mathrm{C}$ proceeded with 
excellent enantioselectivity (92\% ee) [23], as shown in Scheme 7. On the other hand, Bach et al. described that the reduction of benzalacetone using 4 and $\mathrm{BH}_{3}-\mathrm{Me}_{2} \mathrm{~S}$ in $\mathrm{THF}$ at $0{ }^{\circ} \mathrm{C}$ provided a lower enantioselectivity (82\% ee) [24]. Recently, Falck et al. also reported the enantioselective reduction of benzalacetone using CB and air-stable bifunctional thiourea-amine organocatalyst 5, instead of CBS oxazaborolidine catalyst, with a high enantioselectivity (90\% ee) [25]. In this context, we investigated the enantioselective reduction of $\alpha, \beta$-enones as challenging substrates using the oxazaborolidine generated in situ from the chiral lactam alcohol 3 to expand its scope and generality [26].<smiles>CC(=O)/C=C/c1ccccc1</smiles>

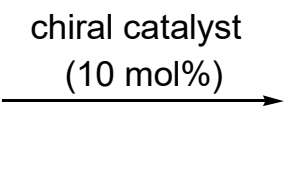<smiles>C[C](O)C=Cc1ccccc1</smiles><smiles>[R]B1OC(c2ccccc2)(c2ccccc2)C2CCCN12</smiles>

$$
\text { 1c } \mathrm{R}=n-\mathrm{Bu}[23]
$$<smiles>C[As]1N[C@@H](c2ccccc2)C(c2ccccc2)(c2ccccc2)O1</smiles>

4 [24]

$$
\begin{aligned}
& \mathrm{CB},-78^{\circ} \mathrm{C} \\
& 92 \% \text { ee }(R)
\end{aligned}
$$

$$
\begin{aligned}
& \mathrm{BH}_{3}-\mathrm{Me}_{2} \mathrm{~S}, 0{ }^{\circ} \mathrm{C} \\
& 82 \% \text { ee }(\mathrm{S})
\end{aligned}
$$<smiles>FC(F)(F)c1cc(NC(=S)N[C@H]2CCCC[C@H]2NCc2ccccc2)cc(C(F)(F)F)c1</smiles>

5 [25]

$\mathrm{CB},-46{ }^{\circ} \mathrm{C}$

$90 \%$ ee $(S)$

Scheme 7. Chiral catalysts for the borane reduction of benzalacetone.

We first examined the effect of the alcohol on the enantioselectivity of the reduction of benzalacetone as a substrate using the chiral lactam alcohol $3(10 \mathrm{~mol} \%)$ and $\mathrm{BH}_{3}-\mathrm{THF}$ at $0{ }^{\circ} \mathrm{C}$ because the reduction with 3 and $\mathrm{BH}_{3}$-THF afforded a complicated mixture as a result of the hydroboration side reaction. We found that the addition of $p$-iodophenol significantly increased the enantioselectivity compared to 2-propanol $[27,28]$ and $p$-halogen substituted phenols as shown in Table 1 . Then, we examined the solvent effect in the reduction with 3 and $p$-iodophenoxyborane. Toluene afforded a higher yield than THF and the polar solvents, dichloromethane $\left(\mathrm{CH}_{2} \mathrm{Cl}_{2}\right)$ and chloroform $\left(\mathrm{CHCl}_{3}\right)$, afforded somewhat lower enantioselectivities (56\% ee and $66 \%$ ee).

Table 1. Asymmetric reduction of $\alpha, \beta$-enones using the chiral lactam alcohol $3{ }^{\text {a }}$.

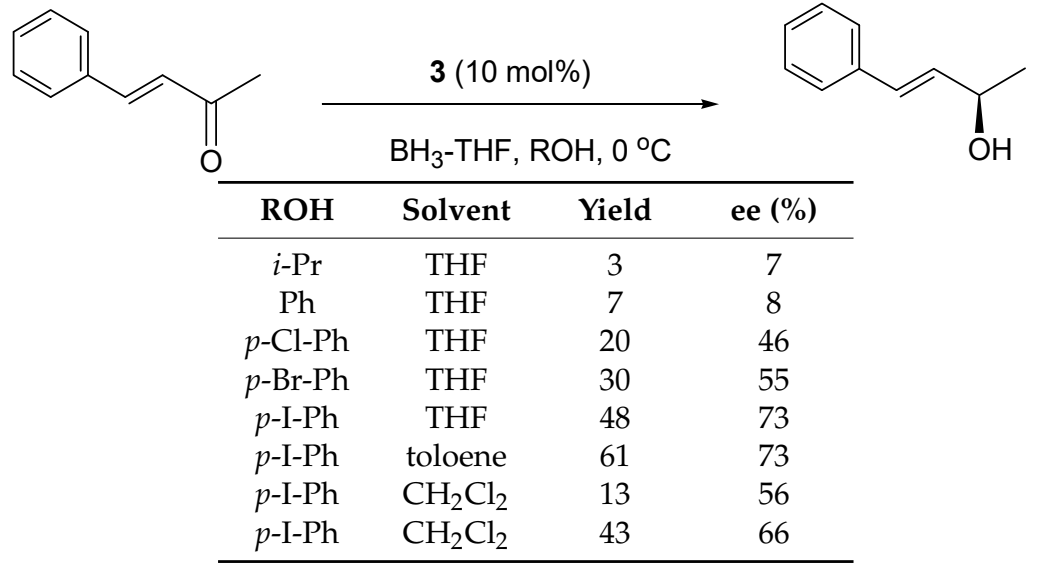

a All reactions were carried out with $10 \mathrm{~mol} \%$ of 3 and 1.2 equiv. of the alcohol and $\mathrm{BH}_{3}-\mathrm{THF}$ at $0{ }^{\circ} \mathrm{C}$ for $2 \mathrm{~h}$. 
Stone demonstrated that Ph-CBS catalyst is more sensitive to temperature change than Me- and Bu-CBS catalysts and indicated that CBS reduction may be optimized to obtain the highest selectivity possible for a given catalyst and ketone by adjusting the temperature [19]. Therefore, we examined the temperature effect on enantioselectivity for the reduction of benzalacetone using the in situ generated p-I-PhO-oxazaborolidine catalyst 1e.

When the reaction temperature is lowered from $0{ }^{\circ} \mathrm{C}$ to $-60{ }^{\circ} \mathrm{C}$, the enantioselectivity increased up to $84 \%$ ee at $-40{ }^{\circ} \mathrm{C}$, and then dropped to $63 \%$ ee at $-60{ }^{\circ} \mathrm{C}$ (Table 2 ). Therefore, the optimal temperature in toluene was found to be $-40{ }^{\circ} \mathrm{C}$. The temperature effect might be attributed to the acceleration of the catalytic cycle as a result of the dissociation of the product $\mathbf{D}$ and the regeneration of the catalyst from the reaction intermediate $\mathbf{C}$ (Scheme 8). Interestingly, we observed that the enantioselectivity was susceptible to the balance between the borane equivalents and catalyst loading. When $8 \mathrm{~mol} \%$ of the chiral lactam alcohol 3 and 1.0 equiv. of $p-\mathrm{I}_{-} \mathrm{PhOBH}_{2}$ were used, the enantioselectivity increased up to $90 \%$ ee.

Table 2. Effect of temperature, ligand loading, and borane equivalent on enantioselectivity for the reduction of benzalacetone using chiral lactam alcohol 3 and $p$-iodophenoxyborane ${ }^{\mathrm{a}}$.

\begin{tabular}{|c|c|c|c|c|}
\hline & O & $\mathrm{BH}_{3}-\mathrm{THF}, p-\mathrm{I}-\mathrm{PhOH}$ & & $\mathrm{OH}$ \\
\hline Temp. $\left({ }^{\circ} \mathrm{C}\right)$ & $3(\mathrm{~mol} \%)$ & $p$-I-PhOBH ${ }_{2}$ (equiv) & Yield (\%) & ee $(\%)$ \\
\hline 0 & 10 & 1.2 & 61 & 73 \\
\hline-20 & 10 & 1.2 & 66 & 81 \\
\hline-40 & 10 & 1.2 & 87 & 84 \\
\hline-60 & 10 & 1.2 & 66 & 63 \\
\hline-40 & 8 & 1.0 & 92 & 90 \\
\hline
\end{tabular}

a All reactions were carried out with $10 \mathrm{~mol} \%$ of 3 and 1.2 equiv of $\mathrm{BH}_{3}$ and $p$-iodophenol in THF.<smiles>O=C1CCC(C(O)(c2ccccc2)c2ccccc2)N1</smiles>

2

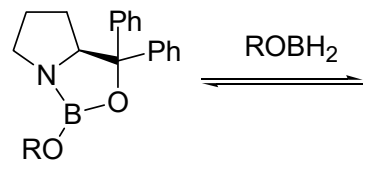

RO

C

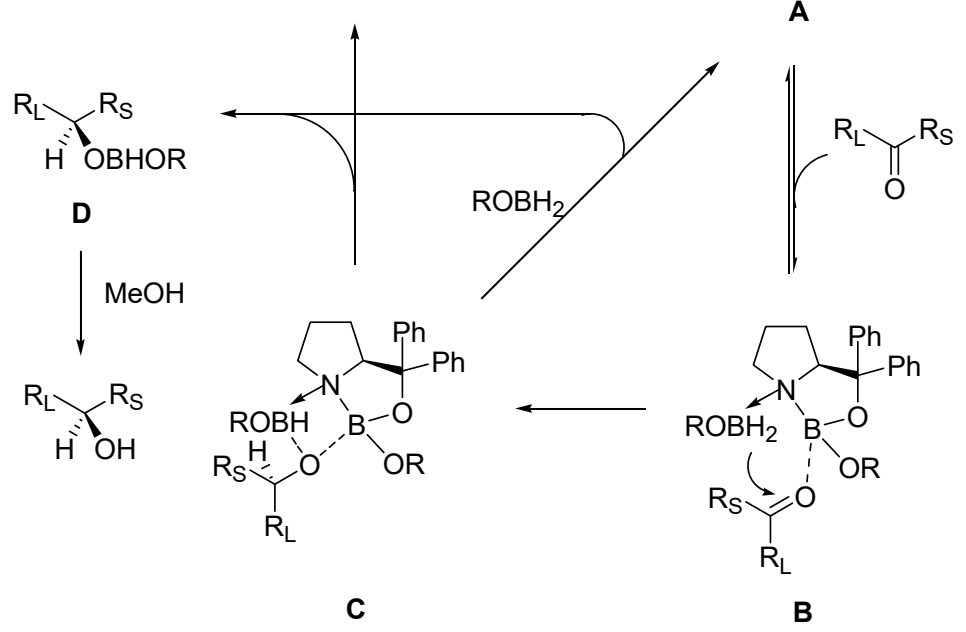

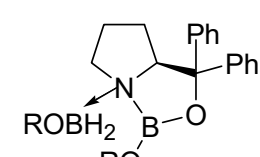

$\mathrm{RO}$

A

Scheme 8. Mechanism of the CBS reduction of ketones, proposed by Core et al.

The absolute configuration of the resulting secondary alcohol was $(R)$, which agreed with the reduction process catalyzed by Bu-CBS 1c [23]. The enantioselectivity was proposed to originate via 
a six-membered transition state B shown in Scheme 8 [4]. Therefore, this result can be explained by a transition state model (Figure 4 ) in which the olefinic part behaves as the large group $\mathrm{R}_{\mathrm{L}}$ and the hydride of 4-I-PhOBH 2 would attack on the Si-face of the carbonyl carbon of benzalacetone to give the (R)-alcohol.

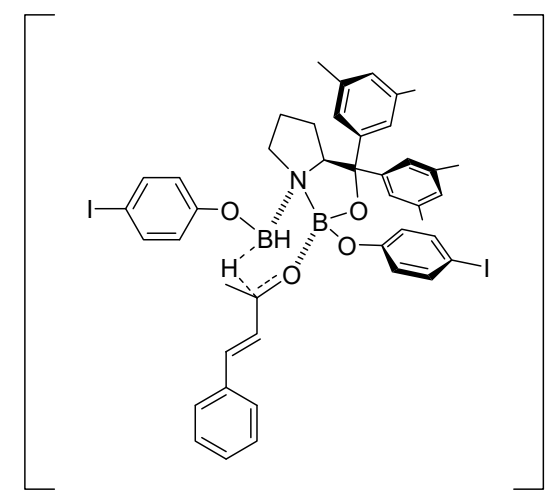

Figure 4. Proposed transition state model.

Under the optimized conditions, we investigated the borane reduction of various $\alpha$, $\beta$-enones to evaluate the scope and limitations of the substrate. As shown in Scheme 9, the reduction of $p$-chloro and $p$-methyl substituted benzalacetones proceeded with a slightly lower enantioselectivity than that of benzalacetone, regardless of their electronic properties. The bulkier 4-(1-naphtyl)-3-butene-2-one was reduced with $86 \%$ ee. The reduction of 6-phenyl-3-buten-2-one proceeded with a slightly lower enantioselectivity ( $83 \%$ ee) compared to that of benzalacetone, possibly due to the lack of conjugation with the benzene ring. Although the reduction of the cyclic enone, 1-acetylcyclohexene afforded a high enantioselectivity ( $85 \%$ ee), the reduction of the exocyclic enone, phenylmethylidenecyclohexanone, revealed a moderate enantioselectivity $(76 \%$ ee). This result can be explained by the less stable s-cis conformation of the exocyclic enone, unlike the s-trans conformation of the cyclic enone and other enones of the transition state (Figure 4).

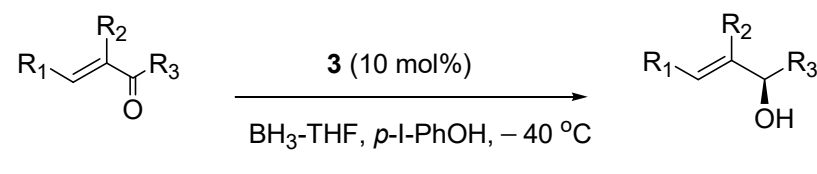<smiles>CC(O)C=Cc1ccccc1</smiles>

$92 \%, 90 \%$ ee<smiles>CC(O)/C=C/c1cccc2ccccc12</smiles>

$84 \%, 86 \%$ ee<smiles>O[C@H]1CCCC/C1=C\c1ccccc1</smiles>

$73 \%, 76 \%$ ee<smiles>Cc1ccc(/C=C/C(C)O)cc1</smiles>

$97 \%, 88 \%$ ee<smiles>C[C@H](O)/C=C/CCc1ccccc1</smiles>

$85 \%, 83 \%$ ee<smiles>C[C@H](O)/C=C/c1ccc(Cl)cc1</smiles>

$95 \%, 88 \%$ ee<smiles>CC(O)C1=CCCCC1</smiles>

$87 \%, 85 \%$ ee

Scheme 9. Asymmetric reduction of $\alpha, \beta$-enones using 3 and $p$-iodophenoxyborane. All reactions were carried out with $10 \mathrm{~mol} \%$ of 3 and 1.2 equiv of $\mathrm{BH}_{3}$ and $p$-iodophenol in $\mathrm{THF}$ at $-40{ }^{\circ} \mathrm{C}$. 


\section{Asymmetric Reduction of Trifluoromethyl Ketones}

Fluorine-containing chiral alcohols have recently been studied as potentially good precursors for preparing ferroelectric liquid crystals [29]. However, because of their high reactivity, the oxazaborolidinecatalyzed asymmetric borane reduction of trifluoromethyl ketones usually affords the corresponding chiral secondary alcohols with a poor enantioselectivity [4], except for the reduction of the trifluoromethyl ketones with Bu-CBS 1c and CB [30,31]. This low enantioselectivity can be explained by the low coordinating ability of the carbonyl oxygen to the oxazaborolidine catalyst and the noncatalytic reduction with borane. It was also reported that the oxazaborolidine 6 derived from L-threonine and $\mathrm{CB}$ at $-90{ }^{\circ} \mathrm{C}$ afforded high enantioselectivities [32]. On the other hand, other methods using the catalyst prepared from (S)-diphenylpyrrolidinemethanol with 9-borabicyclo[3.3.1]nonane (9-BBN) 7 [33], spiroborate ester 8 [34], and electronically tuned-CBS catalyst 1 f with high Lewis acidity [35] have been reported with good to high enantioselectivities and, interestingly, stereochemistry opposite to that of 1c (Scheme 10). Therefore, we set out to investigate the catalytic asymmetric reduction of trifluoromethyl ketones using the simple oxazaborolidine 1a generated in situ from the chiral lactam alcohol 2 and borane $[14,36]$ to clarify its scope and enantioselection.<smiles>O=C(c1ccccc1)C(F)(F)F</smiles>

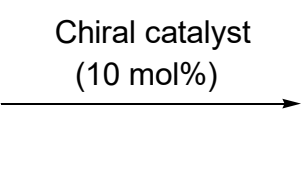<smiles>OC(c1ccccc1)C(F)(F)F</smiles><smiles>[R]B1OC(c2ccccc2)(c2ccccc2)C2CCCN12</smiles><smiles>[R]B1OC(c2ccccc2)(c2ccccc2)C2CCCN12</smiles><smiles>CB1N[C@H]([C@H](C)OS(C)(=O)=O)C(c2ccccc2)(c2ccccc2)O1</smiles>

1c $\mathrm{R}=n-\mathrm{Bu}[30]$

1f $\mathrm{R}=2,4,6-\mathrm{F}_{3} \mathrm{C}_{6} \mathrm{H}_{2}$ [35]

6 [32]

$\mathrm{CB},-78^{\circ} \mathrm{C}$, $90 \%$ ee $(R)$ $\mathrm{BH}_{3}-\mathrm{Me}_{2} \mathrm{~S}, \mathrm{rt}$, $90 \%$ ee $(S)$ $\mathrm{CB},-90^{\circ} \mathrm{C}$, $86 \%$ ee $(R)$

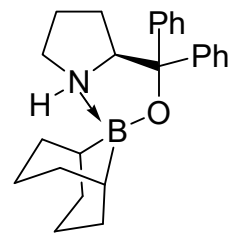

7 [33]

$\mathrm{BH}_{3}-\mathrm{THF}, 0^{\circ} \mathrm{C}$, $93 \%$ ee $(S)$<smiles>c1ccc(C2(c3ccccc3)OC(c3ccccc3)(c3ccccc3)O2)cc1</smiles>

8 [34]

$\mathrm{BH}_{3}-\mathrm{Me}_{2} \mathrm{~S}, \mathrm{rt}$, $82 \%$ ee $(S)$

Scheme 10. Various chiral catalysts for the borane reduction of 2,2,2-trifluoroacetophenone.

We first examined the effect of borane reagents on enantioselectivity for the reduction of trifluoroacetophenone as shown in Table 3. Various borane reagents, $\mathrm{BH}_{3}-\mathrm{THF}, \mathrm{BH}_{3}-\mathrm{Me}_{2} \mathrm{~S}, \mathrm{CB}$, and $p$-I-PhOBH$H_{2}$ were used at room temperature. Although the reduction with $\mathrm{BH}_{3}-\mathrm{Me}_{2} \mathrm{~S}$ or $\mathrm{CB}$ resulted in small enantioselectivities and the use of $p-\mathrm{I}-\mathrm{PhOBH}_{2}$, which was effective for the reduction of aliphatic ketones [17], did not improve the enantioselectivity, the use of $\mathrm{BH}_{3}-\mathrm{THF}$ was found to be optimal as a reducing borane reagent for our method. Further study of the solvent revealed that the polar solvent $\mathrm{CHCl}_{3}$ afforded a significantly higher enantioselectivity (up to $80 \%$ ee) for the reduction with 2 and $\mathrm{BH}_{3}$-THF. However, we observed variable enantioselectivities depending on the storage 
period of $\mathrm{BH}_{3}-\mathrm{THF}$. To our surprise, when a new commercially available $\mathrm{BH}_{3}-\mathrm{THF}$ (stabilized with ca. $0.005 \mathrm{M} \mathrm{NaBH}_{4}$ ) was employed, only lower enantioselectivities (55\% ee) were obtained. These results imply that a properly degraded $\mathrm{BH}_{3}$-THF is superior to the one containing $\mathrm{NaBH}_{4}$-stabilizer possibly due to the butoxyborane species produced by the reduction of THF with $\mathrm{BH}_{3}$-THF during storage, as reported by Nettles et al. [37]. They also described that the addition of a Lewis acid deactivated the $\mathrm{NaBH}_{4}$ stabilizer in $\mathrm{BH}_{3}-\mathrm{THF}$ and that the $\mathrm{BF}_{3}$-THF complex (3-8 mol\%) proved to be the best with a high enantioselectivity for the reduction of acetophenone among the examined Lewis acids. Fu et al. simultaneously reported that the chemo- and enantioselectivities dramatically increased when using an acid ( $5 \mathrm{~mol} \%$ of $\mathrm{BF}_{3}-\mathrm{OEt}_{2}$ or $p$-toluenesulfonic acid) as a scavenger of the $\mathrm{NaBH}_{4}$ stabilizer in $\mathrm{BH}_{3}$-THF for the reduction of a ketone having the chiral 4-phenyl-2-oxazolidinone auxiliary [38]. Therefore, we expected that addition of $\mathrm{BF}_{3}$ could enhance the enantioselectivity for the reduction of trifluoroacetophenone with the oxazaborolidine 1a. The reduction with $2(10 \mathrm{~mol} \%)$ and $\mathrm{BH}_{3}-\mathrm{THF}$ (0.8 equiv.) in the presence of $\mathrm{BF}_{3}(8 \mathrm{~mol} \%)$ provided the $(S)$-alcohol in $85 \%$ yield, with a higher enantioselectivity $\left(60 \%\right.$ ee) compared to that without $\mathrm{BF}_{3}$, implying that the $\mathrm{BF}_{3}$ remaining after scavenging the $\mathrm{NaBH}_{4}$ stabilizer might enhance the enantioselectivity. Accordingly, we carefully examined the effect of $\mathrm{BF}_{3}$ loading on the enantioselectivity, which was not described in the papers mentioned above $([37,38])$. The enantioselectivity increased depending on the $\mathrm{BF}_{3}$ loading and reached $80 \%$ ee at $160 \mathrm{~mol} \%$, which was found to be the best loading after screening for the optimal loading. To clarify the effect of its addition, 8 and $160 \mathrm{~mol} \%$ of $\mathrm{BF}_{3}$ were added to the reduction process using the pure $\mathrm{BH}_{3}$ generated in situ from tetra- $n$-butylammonium borohydride (TBAB) and methyl iodide (MeI) [39], thus producing the (S)-alcohol in high yield and with high enantioselectivities. These results suggested that excess $\mathrm{BF}_{3}$-THF not only deactivated $\mathrm{NaBH}_{4}$ stabilizer, but also actually improved the enantioselectivity.

Table 3. Asymmetric reduction of 2,2,2-trifluoroacetophenone using lactam alcohol $2{ }^{\mathrm{a}}$.

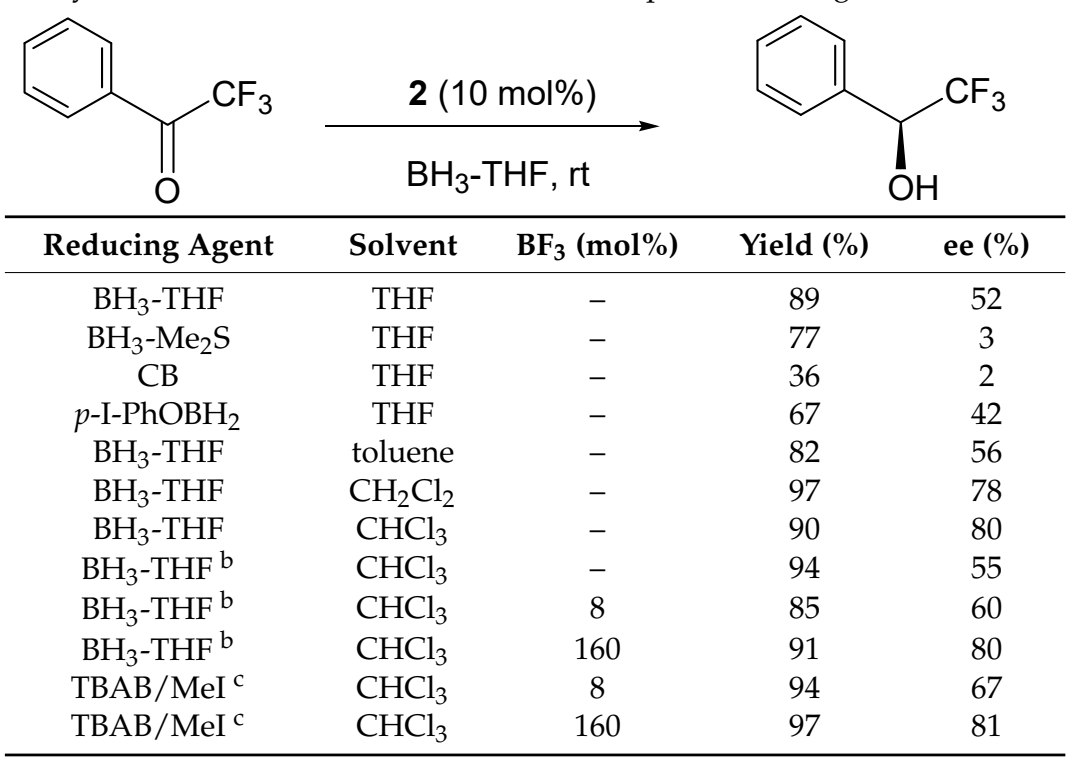

a All reactions were carried out with $10 \mathrm{~mol} \%$ of 2 and 1.2 equiv of $\mathrm{BH}_{3}$ and $p$-iodophenol in THF at $-20{ }^{\circ} \mathrm{C}$.

${ }^{\mathrm{b}}$ New bottle containing approximately $0.005 \mathrm{M} \mathrm{NaBH}_{4} \cdot{ }^{\mathrm{c}} \mathrm{Pure}_{\mathrm{BH}}$ was generated in situ.

The stereochemistry of the resulting secondary alcohol during the reduction with $\mathrm{BH}_{3}$-THF was the same (S)-configuration as that observed for the reductions catalyzed by $\mathbf{1 f}$ [35], 7 [33], and 8 [34], suggesting that the hydride attack on the Re-face of the carbonyl group of trifluoroacetophenone might occur via a typical transition state (Figure 5A) for general CBS reductions. 


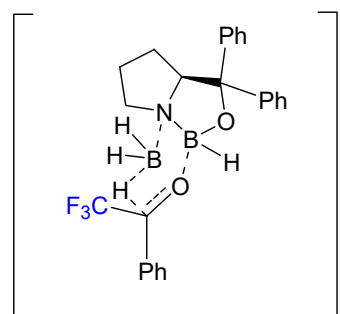

A
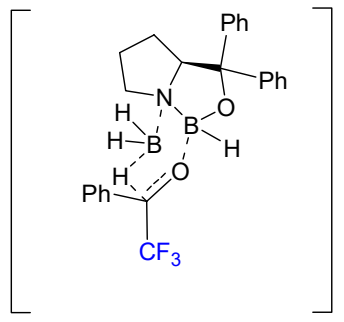

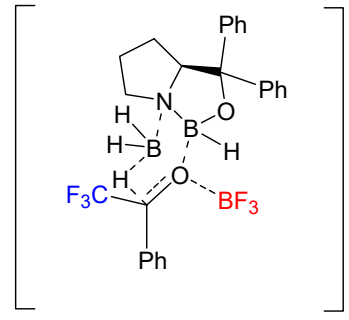

C

Figure 5. Proposed transition state models.

Corey et al. proposed another transition state (Figure 5B) for the reverse (R)-enantioselection occurring hydride attack on the $\mathrm{Si}$-face of the carbonyl group during the reduction with Bu-CBS $1 \mathrm{c}$ and $\mathrm{CB}$ at $-78{ }^{\circ} \mathrm{C}$ due to the electrostatic repulsion between the trifluoromethyl group and the lone pair of the carbonyl group. To clarify whether the addition of $\mathrm{BF}_{3}$ causes a change in the oxazaborolidine catalyst, we carried out ${ }^{11} \mathrm{~B}$ NMR study of the in situ generated oxazaborolidine catalyst in the presence of $\mathrm{BF}_{3}$. The ${ }^{11} \mathrm{~B} \mathrm{NMR}$ analysis revealed that the major signals (+17.7 ppm and $\left.-13.2 \mathrm{ppm}\right)$ of the oxazaborolidine complex with $\mathrm{BH}_{3}$-THF and free oxazaborolidine ( $-27.2 \mathrm{ppm}$ ) did not change upon the addition of $\mathrm{BF}_{3}-\mathrm{THF}$ to the catalyst solution. Thus, an interaction between the oxazaborolidine catalyst and $\mathrm{BF}_{3}$-THF was deemed to be negligible, if any. These results suggested that $\mathrm{BF}_{3}$ might not coordinate to the in situ generated catalyst, but rather coordinate to trifluoroacetophenone, in an anti-relationship to the trifluoromethyl group, thereby stabilizing the complex in the transition state (Figure 5C).

Under the optimized reaction conditions, the reduction of aromatic trifluoromethyl ketones including the para-substituted biphenyl trifluoromethyl ketones proceeded with moderate to high enantioselectivities as shown in Scheme 11. The electron-donating methoxy and phenyl groups of the benzene ring increased the enantioselectivity to 86 and $90 \%$ ee, respectively. The reduction of the biphenyl trifluoromethyl ketone with the methoxy group afforded the (S)-alcohol in $90 \%$ yield with the enantioselectivity of $86 \%$ ee, which is similar to that obtained from the reduction with Bu-CBS 1c or the oxazaborolidine derived from L-threonine and $\mathrm{CB}$ at $-90^{\circ} \mathrm{C}$, but the opposite (S)-configuration [33]. On the other hand, the biphenyl trifluoromethyl ketone with an electron-withdrawing bromo group was reduced with modest enantioselectivity $(71 \%$ ee).<smiles>[R]c1ccc(C=O)cc1</smiles>

$91 \%, 80 \%$ ee<smiles>COc1ccc(C(O)C(F)(F)F)cc1</smiles>

$88 \%, 86 \%$ ee<smiles>OC(c1ccc(Br)cc1)C(F)(F)F</smiles><smiles>OC(c1ccc(-c2ccccc2)cc1)C(F)(F)F</smiles>

$82 \%, 90 \% e^{a}$<smiles>COc1ccc(-c2ccc(C(O)C(F)(F)F)cc2)cc1</smiles>

$90 \%, 86 \%$ ee<smiles>OC(c1ccc(-c2ccc(Br)cc2)cc1)C(F)(F)F</smiles>

$74 \%, 71 \%$ ee

Scheme 11. Asymmetric reduction of various trifluoromethyl ketones using 2. All reactions were carried out with $10 \mathrm{~mol} \%$ of $2,160 \mathrm{~mol} \%$ of $\mathrm{BF}_{3}$ and 0.8 equiv of $\mathrm{BH}_{3}$ in $\mathrm{CHCl}_{3}$ at room temperature.

a Temperature, $40^{\circ} \mathrm{C}$. 


\section{Conclusions}

We have demonstrated that the oxazaborolidine catalysts generated in situ from the chiral lactam alcohol 2 and borane catalyzed the enantioselective reduction of aromatic ketones with high enantioselectivities. Furthermore, in the case of aliphatic ketones and $\alpha$, $\beta$-enones, the use of $p$-iodophenoxyborane improved the enantioselectivities at low temperatures and, in the case of trifluoromethyl ketones, the addition of $\mathrm{BF}_{3}$ enhanced the enantioselectivities at room temperature. These modified methods offer good reproducibility and render the catalytic borane reductions more practical because these catalysts can be easily generated in situ from stable chiral lactam alcohols and borane before use.

Author Contributions: This review article was conceived by Y.K., in consultation with R.C.Y.

Funding: This research was financially supported in part by Tosoh Co., Tokyo, Japan.

Acknowledgments: This paper is dedicated to Tsutomu Katsuki (Kyushu University) for his helpful discussions and encouragement.

Conflicts of Interest: The authors declare no conflict of interest.

\section{References}

1. Wallbaum, S.; Martens, J. Asymmetric syntheses with chiral oxazaborolidines. Tetrahedron Asymmetry 1992, 3, 1475-1504. [CrossRef]

2. Singh, V.K. Practical and useful methods for the enantioselective reduction of unsymmetrical ketones. Synthesis 1992, 605-620. [CrossRef]

3. Deloux, L.; Srebnik, M. Asymmetric boron-catalyzed reactions. Chem. Rev. 1993, 93, 763-777. [CrossRef]

4. Corey, E.J.; Helal, C.J. Reduction of carbonyl compounds with chiral oxazaborolidine catalysts: A new paradigm for enantioselective catalysis and a powerful new synthetic method. Angew. Chem. Int. Ed. 1998, 37, 1986-2012. [CrossRef]

5. Hirao, A.; Itsuno, S.; Nakahama, S.; Yamazaki, N. Asymmetric reduction of aromatic ketones with chiral alkoxy-amine-borane complexes. J. Chem. Soc. Chem. Commun. 1981, 0, 315-317. [CrossRef]

6. Itsuno, S.; Hirao, A.; Nakahama, S.; Yamazaki, N. Asymmetric synthesis using chirally modified borohydrides. Part 1. Enantioselective reduction of aromatic ketones with the reagent prepared from borane and (S)-valinol. J. Chem. Soc. Perkin Trans. 1 1983, 0, 1673-1676. [CrossRef]

7. Itsuno, S.; Ito, A.; Hirao, A.; Nakahama, S. Asymmetric reduction of aliphatic ketones with reagent prepared from (S)-(-)-2-amino-3-methyl-1,1-diphenylbutan-1-ol and borane. J. Org. Chem. 1984, 49, 555-557. [CrossRef]

8. Corey, E.J.; Bakshi, R.K.; Shibata, S. Highly enantioselective borane reduction of ketones catalyzed by chiral oxazaborolidines. Mechanism and synthetic implications. J. Am. Chem. Soc. 1987, 109, 5551-5553. [CrossRef]

9. Qualich, G.; Woodall, T.M. In situ oxazaborolidines, practical enantioselective hydride reagents. Synlett 1993, 12, 929-930. [CrossRef]

10. Yanagi, T.; Kikuchi, K.; Takeuchi, H.; Ishikawa, T.; Nishihara, T.; Kubota, M.; Yamamoto, I. Asymmetric borane reduction of prochiral ketone using chiral bis ( $\alpha, \alpha$-diphenyl-2-pyrrolidinemethanol) carbonate. Chem. Pharm. Bull. 2003, 51, 221-223. [CrossRef] [PubMed]

11. Corey, E.J.; Bakshi, R.K.; Shibata, S.; Chen, C.-P.; Singh, V.K. A stable and easily prepared catalyst for the enantioselective reduction of ketones. Application to multistep syntheses. J. Am. Chem. Soc. 1987, 109, 7925-7926. [CrossRef]

12. Mathre, D.J.; Jones, T.K.; Xavier, L.C.; Blacklock, T.J.; Reamer, R.A.; Mohan, J.J.; Jones, E.T.T.; Hoogsteen, K.; Baum, M.W.; Grabowski, E.J.J. A practical enantioselective synthesis of $\alpha, \alpha$-diaryl-2-pyrrolidinemethanol. Preparation and chemistry of the corresponding oxazaborolidines. J. Org. Chem. 1991, 56, 751-762. [CrossRef]

13. Fujihara, H.; Tomioka, K. Asymmetric protonation of lithium enolate using 5-substituted pyrrolidin-2-one as a chiral proton source. J. Chem. Soc. Perkin Trans. 1 1999, 0, 2377-2381. [CrossRef]

14. Harauchi, Y.; Takakura, C.; Furumoto, T.; Yanagita, R.C.; Kawanami, Y. Effect of $\mathrm{BF}_{3}$ on the enantioselective reduction of trifluoromethyl ketones using a chiral lactam alcohol with borane. Tetrahedron Asymmetry 2015, 26, 333-337. [CrossRef] 
15. Kawanami, Y.; Murao, S.; Ohga, T.; Kobayashi, N. Practical enantioselective reduction ketones using oxazaborolidine catalyst generated in situ from chiral lactam alcohol and borane. Tetrahedron 2003, 59, 8411-8414. [CrossRef]

16. Kawanami, Y.; Mikami, Y.; Hoshino, K.; Suzue, M.; Kajihara, I. Enantioselective reduction of aliphatic ketones using oxazaborolidine catalyst generated in situ from chiral lactam alcohol and phenoxyborane. Chem. Lett. 2009, 38, 722-723. [CrossRef]

17. Masui, M.; Shioiri, T. A practical method for asymmetric borane reduction of prochiral ketones using amino alcohols and trimethylborate. Synlett 1997, 3, 273-274. [CrossRef]

18. Tehan, B.G.; Lloyd, E.J.; Wong, M.G.; Pitt, W.R.; Montana, J.G.; Manallack, D.T.; Gancia, E. Estimation of pKa using semiempirical molecular orbital methods. Part 1: Application to phenols and carboxylic acids. Mol. Inf. 2002, 21, 457-472. [CrossRef]

19. Stone, G. Oxazaborolidine catalyzed borane reductions of ketones: A significant effect of temperature on selectivity. Tetrahedron Asymmetry 1994, 5, 465-472. [CrossRef]

20. Gunes, Y.; Polat, M.F.; Sahin, E.; Fleming, F.F.; Altundas, R. Enantioselective synthesis of cyclic, quaternary oxonitriles. J. Org. Chem. 2010, 75, 7092-7098. [CrossRef] [PubMed]

21. Corey, E.J.; Su, W.-G. Enantioselective total synthesis of bilobalide, A C15 ginkgolide. Tetrahedron Lett. 1988, 29, 3423-3426. [CrossRef]

22. Calaza, M.I.; Hupe, E.; Knochel, P. Highly anti-selective $\mathrm{S}_{\mathrm{N}} 2^{\prime}$ substitutions of chiral cyclic 2-iodo-allylic alcohol derivatives with mixed zinc-copper reagents. Org. Lett. 2003, 5, 1059-1091. [CrossRef] [PubMed]

23. Corey, E.J.; Bakshi, R.K. A new system for catalytic enantioselective reduction of achiral ketones to chiral alcohols. Synthesis of chiral $\alpha$-hydroxy acids. Tetrahedron Lett. 1990, 31, 611-614. [CrossRef]

24. Bach, J.; Berenguer, R.; Farràs, J.; Garcia, J.; Meseguer, J.; Vilarrasa, J. Allylic alcohols of unexpected configuration by oxazaborolidine-catalyzed reduction of $\alpha, \beta$-unsaturated ketones. An explanation based on MO calculations. Tetrahedron Asymmetry 1995, 6, 2683-2686. [CrossRef]

25. Li, D.R.; He, A.; Falck, J.R. Enantioselective, organocatalytic reduction of ketones using bifunctional thiourea-amine catalysts. Org. Lett. 2010, 12, 1756-1759. [CrossRef] [PubMed]

26. Kawanami, Y.; Mikami, Y.; Kiguchi, K.; Harauchi, Y.; Yanagita, R.C. Enantioselective reduction $\alpha$, $\beta$-enones using an oxazaborolidine catalyst generated in situ from chiral lactam alcohol. Tetrahedron Asymmetry 2011, 22, 1891-1894. [CrossRef]

27. Shi, Y.; Cai, D.; Dolling, U.-H.; Douglas, A.W.; Tschaen, D.M.; Verhoeven, T.R. An improved method for chiral oxazaborolidine-catalyzed reduction of 4-chromanone analogs and MK-0499. Tetrahedron Lett. 1994, 35, 6409-6412. [CrossRef]

28. Tschaen, D.M.; Abramson, L.; Cai, D.; Desmond, R.; Dolling, U.-H.; Frey, L.; Karady, S.; Shi, Y.; Verhoeven, T.R. Asymmetric synthesis of MK-0499. J. Org. Chem. 1995, 60, 4324-4330. [CrossRef]

29. Dolbier, W.R., Jr. Fluorine chemistry at the millennium. J. Fluorine Chem. 2005, 126, 157-163. [CrossRef]

30. Corey, E.J.; Cheng, X.; Cimprich, K.A.; Sarshar, S. Remarkably effective and simple syntheses of enantiomerically pure secondary carbinol from achiral ketones. Tetrahedron Lett. 1991, 32, 6835-6838. [CrossRef]

31. Corey, E.J.; Link, J.O.; Bakshi, R.K. A mechanistic and structural analysis of the basis for high enantioselectivity in the oxazaborolidine-catalyzed reduction of trihalomethyl ketones by catecholborane. Tetrahedron Lett. 1992, 33, 7107-7110. [CrossRef]

32. Fujisawa, T.; Onogawa, Y.; Shimizu, M. Structural effect of the oxazaborolidine derived from L-threonine in the reduction of (trifluoroacetyl)biphenyl derivatives with catecholborane. Tetrahedron Lett. 1998, 39, 6019-6022. [CrossRef]

33. Kanth, J.V.B.; Brown, H.C. A new catalytic enantioselective reducing reagent system from (-)- $\alpha, \alpha$-diphenylpyrrolidinemethanol and 9-borabicyclo[3.3.1]nonane, especially effective for hindered and substituted aralkylketones. Tetrahedron 2002, 58, 1069-1074. [CrossRef]

34. Stepanenko, V.; Jesus, M.D.; Correa, W.; Guzman, I.; Vazquez, C.; Cruz, W.; Ortiz-Marciales, M.; Barnes, C.L. Enantioselective reduction of prochiral ketones using spiroborate esters as catalysts. Tetrahedron Lett. 2007, 48, 5799-5802. [CrossRef] [PubMed]

35. Korenaga, T.; Nomura, K.; Onoue, K.; Sakai, T. Rational electronic tuning of CBS catalyst for highly enantioselective borane reduction of trifluoroacetophenone. J. Chem. Soc. Chem. Commun. 2010, 46, 8624-8626. [CrossRef] [PubMed] 
36. Kawanami, Y.; Hoshino, K.; Tsunoi, W. Enantioselective reduction of trifluoromethyl ketones using an oxazaborolidine catalyst generated in situ from chiral lactam alcohol. Tetrahedron Asymmetry 2011, 22, 1464-1466. [CrossRef]

37. Nettles, A.M.; Matos, K.; Burkhardt, E.R.; Rouda, D.R.; Corella, J.A. Role of $\mathrm{NaBH}_{4}$ stabilizer in the oxazaborolidine-catalyzed asymmetric reduction of ketones with $\mathrm{BH}_{3}$-THF. J. Org. Chem. 2002, 67, 2970-2976. [CrossRef] [PubMed]

38. Fu, X.; McAllister, T.L.; Thiruvengadam, T.K.; Tann, C.-H.; Su, D. Process for preparing ezetimibe intermediate by an acid enhanced chemo- and enantioselective CBS catalyzed ketone reduction. Tetrahedron Lett. 2003, 44, 801-804. [CrossRef]

39. Anwar, S.; Periasamy, M. A convenient method for the preparation of oxazaborolidine catalyst in situ using (S)- $\alpha, \alpha$-diphenylpyrrolidinemethanol, tetrabutylammonium borohydride, and methyl iodide for the asymmetric reduction of prochiral ketones. Tetrahedron Asymmetry 2006, 17, 3244-3247. [CrossRef]

C 2018 by the authors. Licensee MDPI, Basel, Switzerland. This article is an open access article distributed under the terms and conditions of the Creative Commons Attribution (CC BY) license (http:/ / creativecommons.org/licenses/by/4.0/). 